\title{
Promoting Active Aging with a paper-based SNS application
}

\author{
Raymundo Cornejo \\ Communication Studies \\ Northwestern University \\ Evanston, IL USA \\ rcornejo@northwestern.edu
}

\author{
Nadir Weibel \\ Computer Science and Engineering \\ University of California, San Diego \\ La Jolla, CA USA \\ weibel@ucsd.edu
}

\author{
Mónica Tentori, Jesús Favela \\ Computer Science \\ CICESE \\ Ensenada, México \\ \{mtentori, favela\}@cicese.mx
}

\begin{abstract}
Social Networking Sites have become useful tools to strengthen communication with family and friends. Older adults, however, are often hesitant to use SNSs and are reluctant adopters of modern communication media. This results in an asymmetric condition, where younger and older adults use different media and communication channels. To balance communication practices we integrated classic media based on pen and paper with online social networks. In this paper we present a 36 weeks deployment study with an extended family $(n=12)$ of the use of Tlatosketch, a hybrid system based on a digital photo frame, and digital pen and paper technology. This combination allows older adults to stay updated on Facebook and to post paper notes to Facebook. Our results show that Tlatosketch provides the older adult with a new media for self-expression, and improves the family social experience, thus helping them remain active while ageing. We close discussing directions for future work.
\end{abstract}

Keywords-Older adults; active aging; social networking sites; digital pen and paper

\section{INTRODUCTION}

Worldwide we are facing a rapid increase in the proportion of older adults due to low birth rates and the rise of life expectancy. This new demographics are putting pressure on healthcare and social security systems, encouraging the promotion of active ageing. Active ageing refers to "the process of optimizing opportunities for health, participation and security in order to enhance quality of life as people age"[1]. Among the guiding principles for active ageing, the Social Protection Committee and the Employment Committee of the European Union highlight the importance of social inclusion [2]. Older people should have equal opportunities to be socially active. Social Network Sites (SNSs, e.g., Facebook, Twitter) show great potential to integrate online social interactions with offline social encounters, fostering current relationships and promoting social gatherings [3]. As social media services are becoming more available due the use of mobile technologies [3, 4], teenagers and young adults are incorporating, and sometimes replacing traditional communication media with SNSs.

Unfortunately, older adults still represent a minority of SNSs' users, and miss important opportunities to foster their social relationships with younger generations, as they still prefer traditional communication channels. In 2014 it was estimated that $11.9 \%$ of American Facebook users were more than 65 years old compared to the $18.4 \%$ aged between $25-34$ [5].
Younger adults' capabilities to early adopt mobile technology contributes to this intergenerational communication gap.

This asymmetry in the communication practices between older adults who use traditional media (e.g., post mail, face-toface, phone calls), and younger adults who use modern communication media (e.g., email, IM, and especially SNSs), might increase older adults' social isolation. Furthermore, the asymmetry might lead to a dead-end communication channel, as younger adults misinterpret or ignore the content that older adults share through traditional communication media.

Prior research suggested digital displays can help to incorporate the older adults into the digital era of social interaction [6, 7]. Digital displays has the potential to narrow this communication asymmetry and enable older adults to strengthen social relationships and rediscover weak ties. Moreover, recent research $[8,9]$ shows how traditional communication media (e.g., paper-based notes, sketched messages) offer rich possibilities for communication and could empower SNSs.

To help balance this communication asymmetry, we explore the impact of the use of Tlatosketch, a paper-based communication tool integrated with a digital frame running a photo lightweight version of a Facebook client. Tlatosketch allows users to visualize photos from Facebook and send notes written on paper to their Facebook wall. Our aim is to explore how this technology preserves traditional communication practices while facilitating the adoption of new ones and its impact on socialization.

\section{TlatoSketch: InTEGRATING SKETCHING WITH DigitAL PHOTO FRAMES}

The Tlatosketch system (Fig. 1 and 2) is based on two components: a system running on a digital frame and a digital pen. The digital pen enables the user to interact with content shared on Facebook (i.e., Tlatoque [7]). The digital pen, based on the Anoto technology (www.anoto.com), enables the user to share paper messages (e.g., text-messages, sketches) back to Facebook [10].

\section{A. Tlatoque}

Tlatoque (Fig. 1, left) is a simple and easy-to-use Facebook client providing older adults with access to their relatives' content shared through Facebook (e.g., photographs). For a particular user, Tlatoque retrieves a list of the user's Facebook friends, and the last ten uploaded photographs. After the photos 
are downloaded, each of them is associated with its Facebook caption and comments. Every other day a web feed is generated, containing the last five photos each relative uploaded to Facebook. The digital frame is configured to read the RSS and retrieve the updated photos. Each photo is displayed for $1 \mathrm{~min}$. Users can interact with the frame through a touch-based interface that allows them to "like" a photo or comment on it.

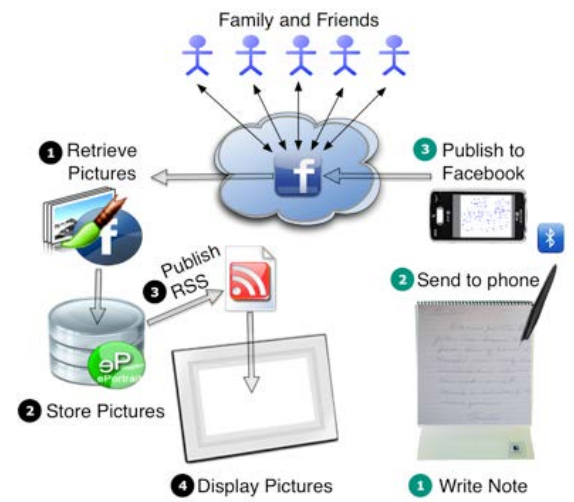

Fig 1. System architecture. Photos are retrieved from Facebook, stored on a database and published over RSS. The digital frame system updates its repository based on the RSS feed. Written notes are then posted as a response to Facebook through a dedicated service deployed on a smartphone.

\section{B. Digital pen and paper}

While Tlatoque enables interactions with the linked social network account through a touch-based interface, this type of input method was not always effective in engaging older adults. Therefore, Tlatoque integrates a lightweight version of the Ubisketch [8] paper-based application (Fig. 1, right). This integration provides to the older adult with paper-based interface. Ubisketch, developed on top of the iPaper framework [11], includes a special notebook printed with the Anoto pattern and an Anoto DP-201 digital pen (Fig. 1). Ubisketch allows the older adult to produce new content and post it on Facebook by using pen and paper interface ${ }^{1}$, while consuming information through the digital display.

After writing a note in the Anoto-patterned notebook, a dedicated paper button with a Facebook icon is used to post the information online. The pen strokes are sent to a specific service that translates them into an image and publishes the image on the Facebook timeline of the older adult. Relatives connected with the older adult receive a Facebook notification about the new content. Since the note appears as a standard photo on Facebook, relatives can comment or like the note as any other photo posted online.

\section{EVALUATION}

We deployed Tlatosketch over a period of 36 weeks with one extended family to evaluate its impact in balancing the communication practices between older adults and young adults.

First, we introduced Tlatoque as a standalone application, and after 12 weeks of use, we introduced Tlatosketch. We followed this two-step introduction of technology to ease the process of learning multiple prototypes, for the older adult.

\section{A. Participants}

Tlatoque and Tlatosketch were deployed with a family of three generations $(\mathrm{N}=12)$ : one 85 year-old female older adult, three female children (avg. age $=59$ ), six grandchildren ${ }^{2}$ (three females, 3 males; avg. age $=30$ ), and one grandniece and one nephew (avg. age $=54$. Younger adults and teenagers participating in the study were active Facebook users, and had been using Facebook for a year and a half before Tlatosketch's deployment.
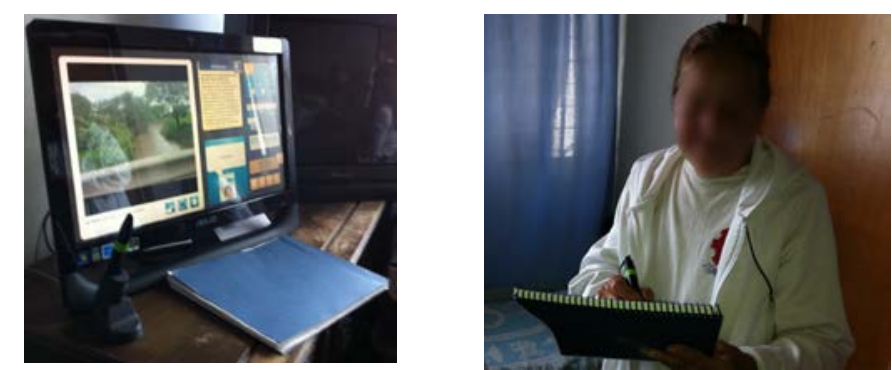

Fig 2. Tlatosquetch deployed in the bedroom of the older adult. Tlatoque running in an all-in-one PC (left) and the older adult posting a written message using the digital pen (right).

Relatives lived in different regions of Mexico and USA, with the majority living in the same city as the older adult $(n=7)$. Relatives living in a different city had infrequent communication with the older adult. Communication between relatives mainly involved social media with limited offline encounters. The older adult was reluctant to the use of technology and had never used a computer or a SNS. Consequently, she followed traditional communication practices to exchange social content with relatives (e.g., sending post-mail and phone calls). Relatives' responses to the older adult messages were infrequent.

\section{B. Study context and procedure}

Data collection included weekly interviews with participants and logs of computer usage. Interviews were individual and semi-structured, and conducted face to face or through instant messaging, video calls, or telephone. Interviews lasted between 30 and 80 minutes, and were recorded and transcribed. On each interview, participants were encouraged to discuss what they found interesting or different when using Tlatosketch, the communication practices and Tlatosketch's usability, and usefulness.

At the beginning of the deployment, the older adult received two brief training sessions, one week apart. During these training sessions, the older adult learned how to use Tlatosketch to browse the digital content, and publish text messages or drawings. The first author analyzed the data following grounded theory techniques [12] to uncover emergent themes about the use and adoption of Tlatosketch, and its impact on participants' communication practices. 


\section{FINDINGS}

In this section, we highlight findings of our analysis, regarding SNS activity, communication, and social developments.

\section{A. Usage and SNS activity}

Over the testing period, we found how the older adult integrated Tlatosketch into her daily routine, and was successful in fostering communication through the photographs' comments in the SNS.

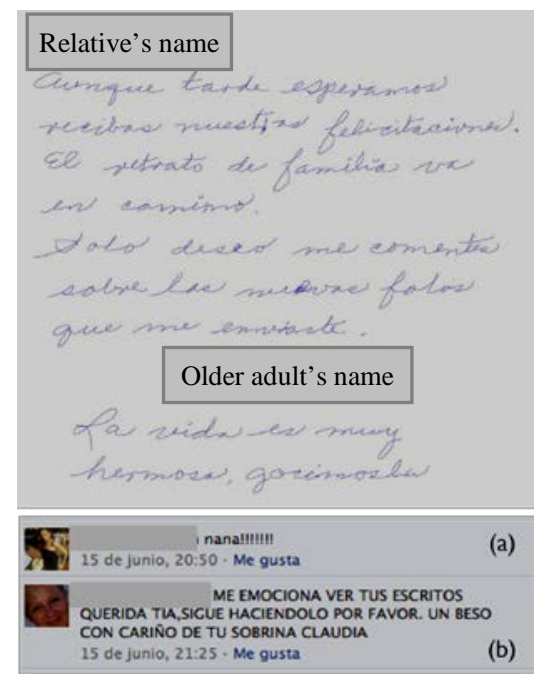

Fig 3. A posted note using Tlatosquetch and two comments from the extended family members, as shown in Facebook.

Message: “[Relative’s name]: Although late, we hope you received our congratulations. The family portrait is on its way. I just wish you could comment on the new photos you sent me. [Older adult's name]. Life is very beautiful, let's enjoy it.”

Comments:(a) “Grandma!!!!!” (b) "I'm excited to see your writing dear Aunt, Dlease keed doing it. A kiss with love from vour niece Claudia.”

The older adult wrote 20 publications using Tlatosketch, all of them containing only text (e.g., Fig. 3). The older adult did not have major problems using the pen and the paper notebook, and relatives were enthusiastic during the study. The form factor of the paper-based technology eased the adoption of the technology for the older adult. The older adult was accustomed to use paper to write letters; therefore transitioning to use Tlatosketch technology was transparent to the older adult. The older adult only had to learn how to charge the pen or send the messages (e.g. placing the pen in the charging dock or tapping the paper buttons), none of these represented hard challenges for the older adult. From the first week of deployment, the older adult showed great enthusiasm to use the digital pen and send messages. The first comments were directed towards thanking her relatives for uploading the photographs she was consulting on Tlatoque. Tlatosketch seem to affect the older adult's mood positively, providing her with calm and personal time, as she had to take time from her "busy" day to send thoughtful messages to her relatives (see Fig 3). "[The use of Tlatosketch] is a special time for me; I sit in my bedroom and think about something personal or relevant for them [referring to her relatives]" $\left(\mathrm{OA}^{3}\right)$.
Relatives had a similar positive perception of Tlatosketch as the older adult. Relatives expressed how the paper-based technology evolved from a "toyish" application to a tool that truly supports informal communication with the older adult. "I see how she writes to my cousin; she can express better her feelings [referring to the use of Tlatosketch] " (Daughter).

\section{B. Types of use: self-expression and communication}

We found that the richness of the content generated on paper gives a more engaging social experience to the older adult. The use of a paper-based interface provides a new mean for selfexpression, communication, and encourages the older adult to be an active writer.

Prior deployment, the older adult's main communication media was her landline phone or social visits in her home. Nevertheless, these social events with relatives were rather sporadic, particularly with those living away or with younger relatives with busy schedules. Tlatosketch allowed the older adult to choose freely when to start a social interaction by sending written messages to the desired relative. "I like to write, now I can take advantage [of Tlatosketch] and write whatever I think; drawing my thoughts or something I want to communicate [on paper]", (OA).

The freedom provided by paper, encouraged the older adult, not only to maintain communication, but also to be creative when sharing written messages with her relatives. Before Tlatosketch, the older adult had a routine of "clipping” articles from a local newspaper that somehow could be relevant to her relatives. These articles were stored until she handed them over to the corresponding relative during face-to-face visits or through postal mail. Therefore, these "clippings" might be forgotten if relatives did not visit the older adult within the next days after storing them. Other times the older adult was not aware if the relative received the postal mail with the clipping. With Tlatosketch, the older adult took advantage of the direct sharing channel, integrating the content of the articles in her posts. The older adult incorporated the news article routine into the use of Tlatosketch by summarizing the relevant aspects of the news into written messages. Furthermore, relatives could also communicate back by commenting the image of the written message that was posted into the SNS. In addition, Tlatosketch catalyzed creative publications and personal thoughts that the older adult shared, as a literary art (e.g. poems). "She [referring to the older adult] can express herself [referring to poems or news]; she can express anything with any of us", (Daughter).

Having this content shared by the older adult with her own handwriting also influenced how her relatives perceived her personality. Most of the messages had the imprinted personality of the older adult. This imprinted personality is currently lost in text-based messages since Facebook users share messages with a standard font type. Relatives expressed that these "snapshots of personality" from the older adult's messages reminded them of the times when she did share with them printed and written messages

Tlatosketch provided a new communication media to stay connected with relatives living away. Although Tlatosketch 
presented itself as a slimmer communication channel in terms of media richness, paper notes were an appropriate mean for enabling asynchronous communication with these relatives scattered in different locations. "It is easier [than calling them], it is more personal. They can read it calmly and they can keep it if they want to. With phone calls it is just voice and can be forgotten", (OA).

For relatives, Tlatosketch messages prompted sporadic conversations over phone calls to talk further about the "asynchronous" messages shared online. "I saw her message about how much she liked the photos, so the other day I called her and we talked about [the photos] and we talked about past memories when I used to live in the same city", (Nephew).

However, the purpose of Tlatosketch of being an alternative to allow the older adult to publish freely in the SNS created communications breakdowns during the first weeks of deployment. Relatives kept using traditional SNS action streams (e.g. direct messages, comments or posts), and the older adult used digital pen messages published in her wall's SNS account. Therefore, a few relatives expected to see the messages in the SNS's chat rather than looking at them as images posted in the SNS. This confusion caused messages' misplacement. To cope with these issues, relatives incorporated new strategies into their communications practices. For example, they started to tag the names mentioned in the text of the messages sent by the older adult. "I was about to tag [my cousin], to make sure he reads the message. Then I noticed he [had already] "liked" the message”, (Grandson).

\section{Writing skills}

Participants commented how the system helped the older adult to practice her writing, an activity she was doing less frequently in recent years. The older adult used Tlatosketch in a private environment where she could dedicate sufficient time to create thoughtful messages for her relatives.

Resuming handwriting practices, by either transcribing the local news or creating poems, is an activity that demanded an effort, which seemed to benefit the older adult. Relatives acknowledged how the older adult was improving her communication and writing skills with each message. Furthermore, the older adult felt more mentally active while creating the written messages for her relatives. The process of understanding the news and translating the essential meaning of the news into the message affected positively on the older adult's perception about her own efficacy.

Daughter: "She's writing again, her handwriting has improved and now she is finishing the sentences. Before [Tlatosketch] she used to write incomplete ideas".

OA: “[Tlatosketch] gives me reason to 'keep my brain going'; not just... like not using it I guess..."

Beyond the improvement in the perceived writing skills, participants also explained that the older adult perception towards technology changed. Now the older adult seems more open to the use of new communication media. "Because now she is using more technology, she knows about computers and communication technologies", (Niece).
Overall, we feel that the Tlatosketch allowed this change of perception and might help in bridging the SNS intergenerational communication gap.

\section{CONCLUSIONS AND FUTURE WORK}

The primary contribution of this work is to articulate the design space of digital pen and paper in SNSs, and explore their efficacy to bridging the gap between the digital era of social interaction and traditional communication practices. Although we do not pretend to generalize our findings to the entire population of older adults, we believe Tlatosketch is a simple and easy-to-use Facebook client that extends its functionality with a digital pen and a paper. Instead of only designing to provide content to the older adult, the paper-based interface provides to the older adult a new self-expression media to create content online and improve her social experience.

More research is required to explore how providing content generation tools to the elderly could affect their social and communication practices into SNSs. Having these services, not only could narrow the intergenerational gap of the use of technology for older adults, but could also help to promote other forms of social inclusion where older adults can contribute in related community themes. Exploring older adults' participation in community concerns might also alleviate access problems where older adults who have physical disabilities are unable to participate in community meetings. By promoting social participation through lightweight SNSs services, older adults might have a positive effect in their wellbeing.

\section{REFERENCES}

[1] European Union: 'Demography, active ageing and pensions', (Union, P.O.o.t.E., 2012)

[2] European Union Social Protection Committee and the Employment Committee: 'Guiding Principles for Active Ageing and Solidarity between Generations', (2012)

[3] Barkhuus, L., and Tashiro, J.: 'Student socialization in the age of facebook'. Proc. Proceedings of the 28th CHI, Atlanta, Georgia, USA, 2010 pp.133142

[4] boyd, d.m., and Ellison, N.B.: 'Social network sites: Definition, history, and scholarship’, J COMPUT-MEDIAT COMM, 2007, 13, (1)

[5] comScore: 'Facebook', (MediaDashboard, c., 2014)

[6] Bothorel, C., Lohr, C., Thépaut, A., Bonnaud, F., and Cabasse, G.: 'From individual communication to social networks: evolution of a technical platform for the elderly'. Proc. 9th ICOST, Montreal, Canada, 2011 pp.145152

[7] Cornejo, R., Tentori, M., and Favela, J.: ‘Ambient Awareness to Strengthen the Family Social Network of Older Adults', JCSCW, 2012, pp. 1-36

[8] Cowan, L.G., Weibel, N., Pina, L.R., Hollan, J.D., and Griswold, W.G.: 'Ubiquitous sketching for social media'. Proc. 13th MobileHCI, Stockholm, Sweden, 2011 pp.395-404

[9] Piper, A.M., Weibel, N., and Hollan, J.: 'Audio-enhanced paper photos: encouraging social interaction at age 105'. Proc. CSCW, San Antonio, Texas, USA, 2013 pp.215-224

[10] Weibel, N., Cowan, L.G., Pina, L.R., Griswold, W.G., and Hollan, J.D.: 'Enabling social interactions through real-time sketch-based communication'. Proc. UIST, New York, New York, USA, 2010 pp.405406

[11] Norrie, M.C., Signer, B., and Weibel, N.: 'General Framework for the Rapid Development of Interactive Paper Applications'. Proc. CoPADD 2006, Banff, Canada, November 4, 20062006 pp.9-12

[12] Holtzblatt, K., Wendell, J.B., and Wood, S.: 'Rapid Contextual Design: A How-to Guide to Key Techniques for User-Centered Design' (Elsevier Science, 2004, 1st edn,2004) 